\title{
Editorial
}

\section{Analysis of the potential impact of the latest Asbestos Survey Guide upon Asbestos surveys and surveyors in the United Kingdom}

\author{
Journal of Building Appraisal (2010) 6, 1-3. doi:10.1057/jba.2010.10
}

\section{INTRODUCTION}

The Health and Safety Executive (HSE) issued a document, Asbestos: The Survey Guide, in January 2010 (HSE, 2010). Although not driven by new legislation, and indeed still underpinned by the Control of Asbestos at Work Regulations 2002 (HMSO, 2002) and the Control of Asbestos Regulations 2006 (HMSO, 2006), the instructions contained within this document could revolutionise the practice of undertaking Asbestos surveys within the United Kingdom's commercial building stock. The special provisions of these guidelines in respect to Asbestos surveying are compared by the editor to those within the HSE's ACOP Work with Materials Containing Asbestos Code of Practice and Guidance, issued in 2006 (HSE, 2006). This code of practice does very little to directly control Asbestos surveys, perhaps leading to a commonly held view that up until now surveys lacked a common approach and consistency (RICS, 2003). The Royal Institution of Chartered Surveyors (RICS) guidelines, Asbestos and Its Implications for Members and Their Clients, RICS (RICS, 2003), is also used as reference for the practice of Asbestos surveying or inspecting pre-2010.

\section{ANALYSIS AND DISCUSSION}

The use of Asbestos-containing materials (ACMs) within buildings was not totally prohibited in the United Kingdom until 1999. This means any building that completed pre-millennium could potentially contain Asbestos fibres, an identified fatal health risk, once disturbed and allowed to become airborne. Using legislation such as CAWR 2002, and CAR 2006, the UK government sought to establish the role of duty holders to be responsible for the duty of care required in respect of non-exposure of people to Asbestos fibres. It also sought to make active management of the risks associated with Asbestos mandatory, and suggested actions required to ensure this is undertaken correctly. One such measure is the Asbestos survey. Regulation named three intensities of survey: Type 1 (visual only); Type 2 (visual + sampling); and Type 3 (Invasive Inspection, dismantling where required and sampling). The professional duties of a Building Surveyor require, as a matter of course, visual identification of suspected ACMs to be part of undertaking any stock survey of a pre-1999 building. This is a factor identified by RICS who warned Chartered Surveyors that courts tend to give weight to the status of the surveyor and find in favour of a more naive client in cases of missed ACMs (RICS, 2003). However, It has been also possible for the general Building Surveyor to include more specialist Asbestos survey work among the list of services offered. Taking the guidelines at face value, which must be so, it would seem that Asbestos survey work could in the future become solely the province of the specialist, highly trained, widely experienced, professionally organised and fully licensed Asbestos contractor. This editorial seeks to identify 
instructions from within the guide, which by direct term or sheer practicality would support this view.

A major change outlined by HSE is that the previous three-level survey regime is reduced to two (HSE, 2010). These are now the Management Survey (MS) and the Refurbishment and Demolition Survey (RDS). The latter, being similar in nature to the Type 3, is linked to the requirements under the Construction Design and Management Regulations 2007 to provide full information pre-tender on any issue that could become a health and safety issue during the undertaking of any construction and demolition contracts. This effectively requires a RDS to be undertaken before any refurbishment or rehabilitation works are planned and brought to tender. The MS is an amalgam of Type 1 and Type 2 surveys, with a requirement as before to actively manage any suspected ACMs. Unlike previous guidelines, there are no requirements for sampling, providing any visually identified ACM is managed as being active. HSE instruct that a material does contain Asbestos unless the surveyor strongly believes it not to contain Asbestos, rather than the previous suspicion of a material possibly containing Asbestos. This puts a greater duty upon the surveyor to deem materials as being suspected ACMs. The guidelines accept a possible combined approach of visual identification, sampling and RDS of just those areas earmarked for refurbishment work. Who can, however, practically undertake this survey work?

Perhaps, a defining feature of the typical building survey is the caveat. Examples from many Building Surveying caveats might be that the survey is undertaken from ground level only, the surveyor will not lift fixed floor coverings, they will not test drains and so on. HSE state that, unless absolutely necessary, an Asbestos survey should be free from restrictive caveats: 'Survey restrictions and caveats seriously undermine the management of Asbestos in buildings' (HSE, 2010). Any areas unavailable for survey must be presumed as containing Asbestos and must be managed as though such were a fact: "Any area not accessed or inspected must be presumed to contain Asbestos unless there is strong evidence that it does not' (HSE, 2010). HSE also cite a need for a preliminary risk assessment for the survey to be done as part of a four-stage pre-survey process. These include planning, information gathering, preparing a plan of action and performing a risk assessment, and for discussion between surveyor and duty holder to take place in order to plan and fully resource the survey. This advice was given by RICS to its members involved in specialist Asbestos work (RICS, 2003). However, not all current Asbestos specialists are chartered. Should the survey require sampling, then HSE insist that this is done by a licensed person, effectively meaning that a surveyor who was not a licensed Asbestos contractor would need to be accompanied by such a contractor to take any samples and undertake any intrusive work. These features might make specialist Asbestos surveys less attractive to the general Building Surveyor, even if they were practically able to undertake them.

The guide sets down requirements for identification of competency, which would preclude many non-specialist surveyors and also some specialist ones. Competency is not a new issue and RICS advised members to study for a relevant 'Working With Asbestos' certificate, and for clients to formally check documentary evidence of a surveyor's competence; however, they also noted that, 'There is currently no mandatory qualification for Asbestos surveyors, and anyone including surveyors can provide the service providing that they are competent and have the necessary specialist skills and experience appropriate for the task' (RICS, 2003). What appears to have changed from that position is the degree of evidence required to prove competence. Although current qualification possession is cited as counting towards competence, it is not a proof of such: 'The P402 qualification on its own does not demonstrate competency. Individuals must have at least six months relevant practical field experience on Asbestos surveys under the supervision 
of experienced and qualified personnel' (HSE, 2010). HSE also cite the need for experience to include significant prior knowledge of the type of building to be surveyed, which may preclude some Asbestos Surveyors with long periods of field experience. Duty holders are required to check individual qualifications and testaments to a successful track record of work completed on similar types of buildings. They must check that the surveyor's organisation has the required insurances in place, has adequate plans in place to manage the survey work, is properly resourced and knows the extent of its own limitations (HSE, 2010). Finally, any sample analysis company must be checked to ensure that they and their staff are competent to test ACMs. With such high requirements for proof of competency the number of surveyors available to tender for Asbestos surveying work must significantly diminish.

Finally, an admission was made by RICS that the guidance on performing Asbestos surveys was issued by various bodies, thus leading to 'little communality' (RICS, 2003) in the survey produced. HSE have, however, produced a very comprehensive description of the required survey document, both in terms of its content and its format. HSE also prescribe how the survey should be completed in terms of organisation, order of inspection and definition of 'systematic' (HSE, 2010). This should standardise survey reports, but might require specialist inspectors from known surveying backgrounds to adopt a report-writing approach that more closely resembles a building survey than do some of the commercial Asbestos reports currently observed by the Editor.

\section{CONCLUSION}

The newly issued HSE Asbestos surveying guidelines are clearly very prescriptive. Strict adherence to the terms will greatly enhance the quality of Asbestos surveying, which should have a beneficial effect upon general Asbestos management. One issue identified by the Editor is the likelihood that general Building Surveyors may become excluded from undertaking Asbestos-related work, and even some specialists may too find their experience insufficient to tender for work. Factoring in the additional difficulties that will be faced by new entrants to the Asbestos-surveying industry and in using basic supply and demand economics, this may drive up the costs of having the survey work completed. However, approved code of practice (ACOP) understands the need for reasonable practicality (HSE, 2006). In terms of, for example, provision of one-off expensive access equipment in order to remove a caveat previously borne out of economic practicality does the Asbestos Survey Guide in the prescription of its terms conflict with ACOP philosophy, or does every high factory or warehouse ceiling really actually need to be managed as being the site of active ACMs, because of the cost of access equipment and specialist surveyors used to working at such heights. The guidelines are new; those involved in the industry can only wait and see how they do impact upon the Asbestos surveys and surveyors in the future. Journal of Building Appraisal will look forward to assessing this in a future edition.

\section{REFERENCES}

HMSO. (2002) Statutory Instrument 2645, Control of Asbestos at Work Regulations. London: The Stationary Office. HMSO. (2006) Control of Asbestos Regulations. London: HMSO.

HSE. (2006) Work With Materials Containing Asbestos, Code of Practice Document. London: HSE Books.

HSE. (2010) Asbestos: The Survey Guide, HSG246 Guidance Document. London: HSE Books.

RICS. (2003) Asbestos and Its Implications for Members and Their Clients. Coventry, UK: RICS Business Services Publication.

Simon Mclean

Managing Editor 